\title{
Field-Weakening Performance of Interior Permanent-Magnet Motors
}

\author{
Wen L. Soong, Member, IEEE, and Nesimi Ertugrul, Member, IEEE
}

\begin{abstract}
This paper compares the field-weakening performance under rated and overload conditions of synchronous reluctance and interior permanent-magnet motors against that of a baseline 2.2-kW induction machine. Four prototype rotors based on axially laminated and multiple-barrier designs were built and tested in the same induction machine stator. Field-weakening performance was estimated based on $50-\mathrm{Hz}$ load tests at reduced voltage. It was found that the performance of the axially laminated synchronous reluctance machine was comparable with the induction machine while the interior permanent-magnet motors offered significantly better output power above rated speed. The multiple-barrier interior permanent-magnet motor design gave the most promising field-weakening performance.
\end{abstract}

Index Terms-Field-weakening performance, interior permanent-magnet motor, motor testing.

\section{INTRODUCTION}

A PPLICATIONS such as electric vehicle traction drives require an ability to operate at constant power over a wide speed range, good overload performance, and high efficiency, especially at light-load operation at higher speeds (see Fig. 1). These characteristics allow the best utilization of the limited battery capacity and minimization of the size and weight of the motor and drive.

A convenient measure of field-weakening performance is the constant power speed range (CPSR), which is the speed range at which the drive can maintain constant power with limited values of voltage and current.

A conventional line-start induction machine (IM) typically offers a CPSR of about 2 to 3 and moderate efficiency both at rated speed and under high-speed/light-load conditions. This performance could be improved by optimizing the motor design for inverter operation.

Early work [1] examined single-barrier interior permanentmagnet (IPM) machines. These offered higher efficiency up to rated speed, but had limited field-weakening range and low efficiency under high-speed/light-load conditions due to the need for large stator currents to suppress the high back electromotive force (EMF) voltage.

Paper IPCSD 02-036, presented at the 2000 Industry Applications Society Annual Meeting, Rome, Italy, October 8-12, and approved for publication in the IEEE TRANSACTIONS ON INDUSTRY APPLICATIONS by the Electric Machines Committee of the IEEE Industry Applications Society. Manuscript submitted for review May 1, 2000 and released for publication May 28, 2002. This work was supported by a Small Australian Research Council Grant.

The authors are with the Electrical and Electronic Engineering Department, University of Adelaide, Adelaide, SA 5005 Australia (e-mail: wen.soong@adelaide.edu.au; nesimi.ertugrul@ adelaide.edu.au).

Publisher Item Identifier 10.1109/TIA.2002.803013.

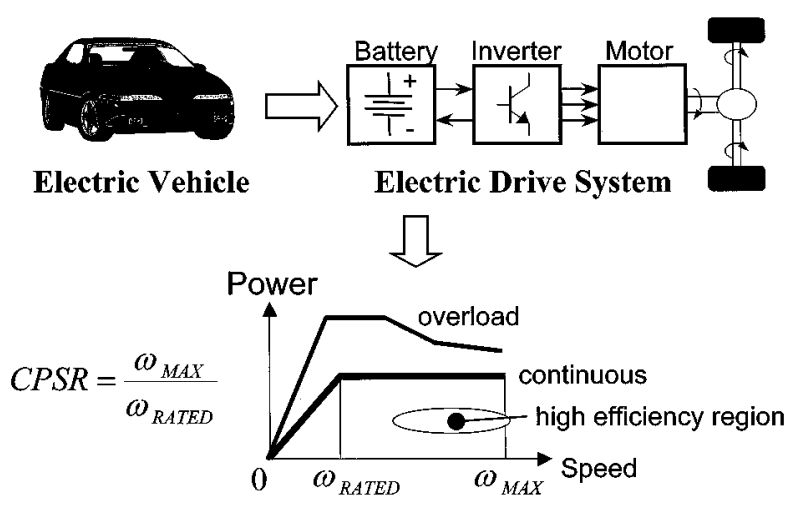

Typical Motor Drive Performance

Fig. 1. Electric vehicle drive system requirements.

Over the last ten years, there has been considerable interest in the axially laminated and the (radially laminated) multiple-barrier forms of synchronous reluctance (synchrel) machines [2], [3].

It has been recognized that adding relatively weak permanent magnets to a synchrel motor can produce an IPM motor with a substantially enhanced field-weakening performance [2], [4]-[8]. In particular, it has been found that the widest field-weakening performance is obtained when the magnet flux linkage $\Psi_{m}$ is given by

$$
\Psi_{m}=L_{d} I_{0}
$$

where $L_{d}$ is the direct-axis ( $d$-axis) inductance and $I_{0}$ is the rated current. (In this paper, the IPM motor convention is used, where the $d$-axis is the magnet axis or the least inductive axis.) Designs which fulfill this criterion are called optimal field-weakening IPM motor designs.

This paper compares the experimental field-weakening performance of the five rotors shown in Figs. 2 and 3. Although the rotor designs have not been optimized for field-weakening performance, the results should give some indication of their relative field-weakening performance potential.

The rotors are as follows:

- Rotor 1 -conventional commercial squirrel-cage induction rotor;

- Rotors 2 and 3-axially laminated synchrel and axially laminated IPM rotors, similar in cross section and consist of alternate layers of laminations and insulating material for the synchrel rotor and alternate layers of laminations and thin flexible magnet sheet for the IPM rotor (see Fig. 2); 


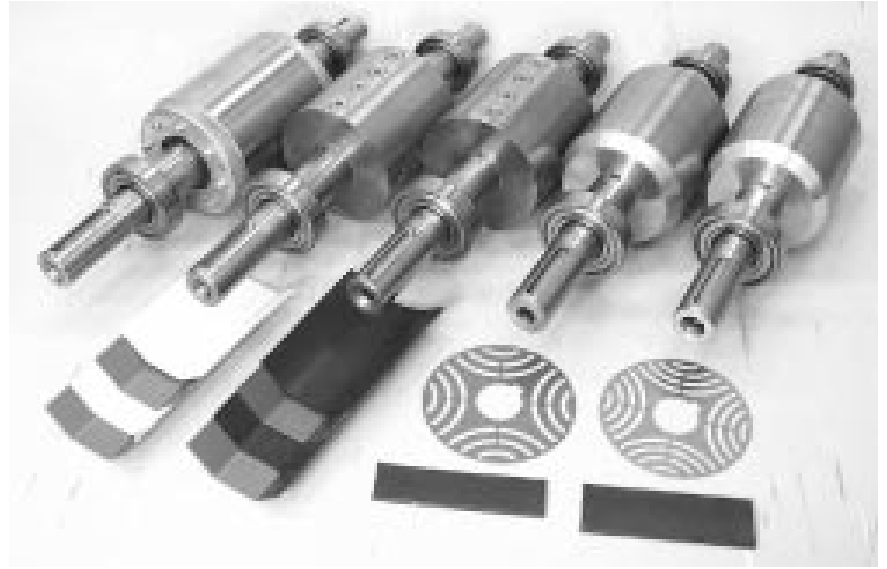

Fig. 2. The five 2.2-kW rotors. From left to right: Rotor 1: squirrel-cage induction; Rotor 2: axially laminated synchrel (lamination/insulating material); Rotor 3: axially laminated IPM (lamination/flexible magnet); Rotor 4: three barrier; and Rotor 5: four barrier.

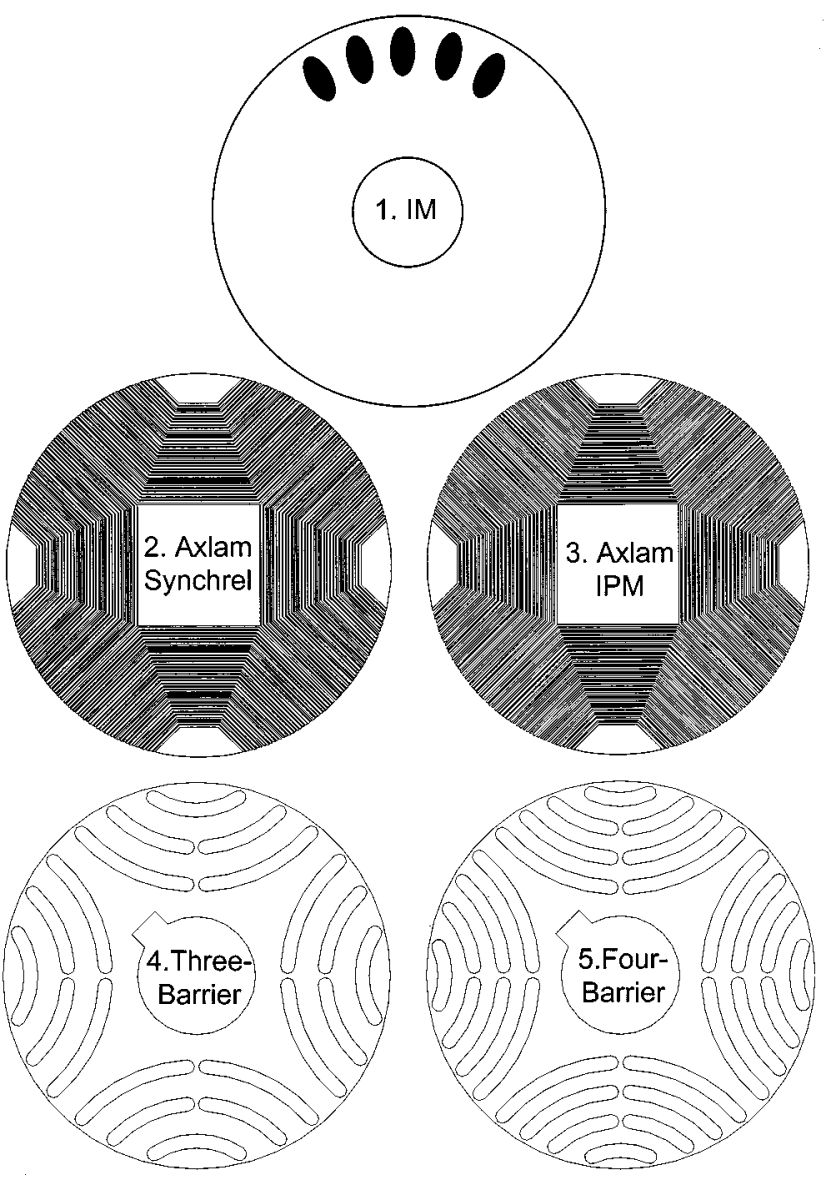

Fig. 3. Cross sections of the induction, axially laminated, and multiple-barrier rotors shown in Fig. 2.

- Rotor 4-three-barrier (that is, three flux barriers per pole) machine (MB-3) without magnets (Rotor 4a) and with magnets (Rotor 4b);

- Rotor 5-four-barrier machine (MB-4) without magnets (Rotor 5a) and with magnets (Rotor 5b).

All the rotors have the same stack length and air gap and were tested in the same stator under the same conditions.

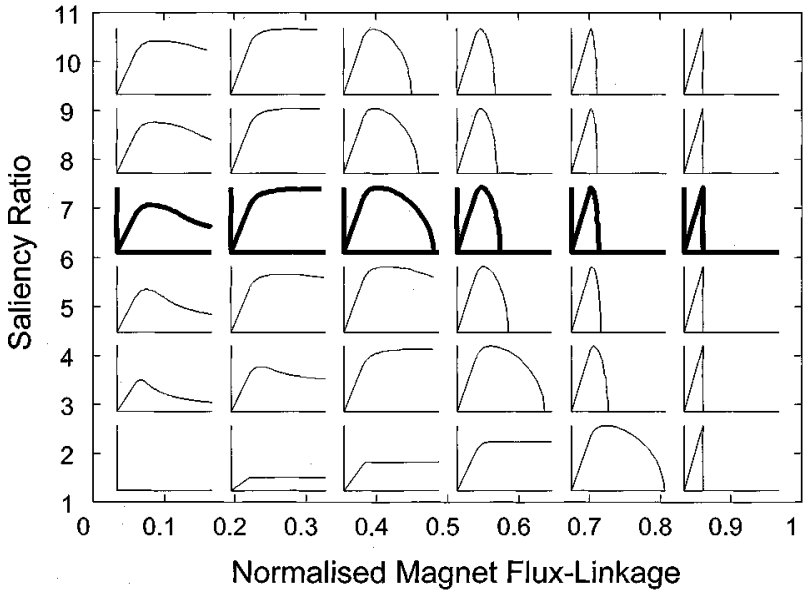

Fig. 4. Power versus speed characteristics as a function of the saliency ratio and normalized magnet flux linkage [9].

\section{THEORETICAL BACKGROUND}

Previous work has investigated the optimal field-weakening design of synchrel, surface permanent-magnet (SPM), and IPM motors [4], [6]. With appropriate normalization, the shape of the field-weakening power versus speed characteristic of these motors can be characterized by only two parameters [9]: 1) the saliency ratio $\left(\xi=L_{q} / L_{d}\right.$, where $L_{q}$ is the quadrature-axis inductance) which is a measure of the synchronous reluctance nature of the machine and 2) the normalized magnet flux linkage $\Psi_{m n}$, which is a measure of the permanent-magnet (PM) nature of the machine.

Fig. 4 illustrates the variations in the shape of the power versus speed characteristics of IPM designs with different values of saliency ratio and normalized magnet flux linkage. Designs which lie on the $x$ axis have a saliency ratio of unity and are SPM designs, while designs which lie on the $y$ axis have no PMs and are, hence, synchrel designs. All other designs are IPM motors.

The curves in bold show the effect of adding permanent magnet material to a synchrel design of saliency ratio of approximately 7. Moving from left to right, adding PM material initially improves the field-weakening characteristic, but adding too much results in a machine which has no field-weakening capability.

From Fig. 4, it is evident that there is an optimum mix of the two parameters which yields a wide field-weakening region. This corresponds to the optimal IPM field-weakening criterion given earlier in (1). Fig. 5 shows a contour plot of CPSR against the two parameters with the optimal field-weakening IPM motor design line highlighted [9]. It also shows the location of the prototype rotors based on the unsaturated motor parameters measured in Section IV.

Note that none of the prototype machine designs are optimal field-weakening designs. Based on the CPSR, Fig. 5 predicts that the IPM machines will have the best field-weakening characteristics.

IPM machines can generally only produce an ideally flat constant power characteristic at the value of stator current given by (1). Fig. 6 shows the field-weakening performance at twice rated current for IPM machines which are optimal field-weakening 


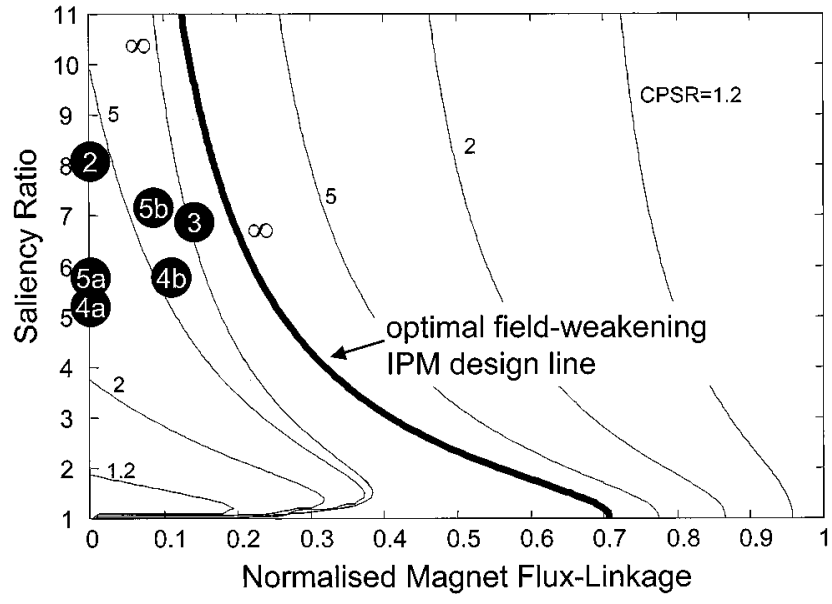

Fig. 5. Contour plot of CPSR as a function of the saliency ratio and normalized magnet flux linkage showing the optimal IPM design line and location of the test motors.

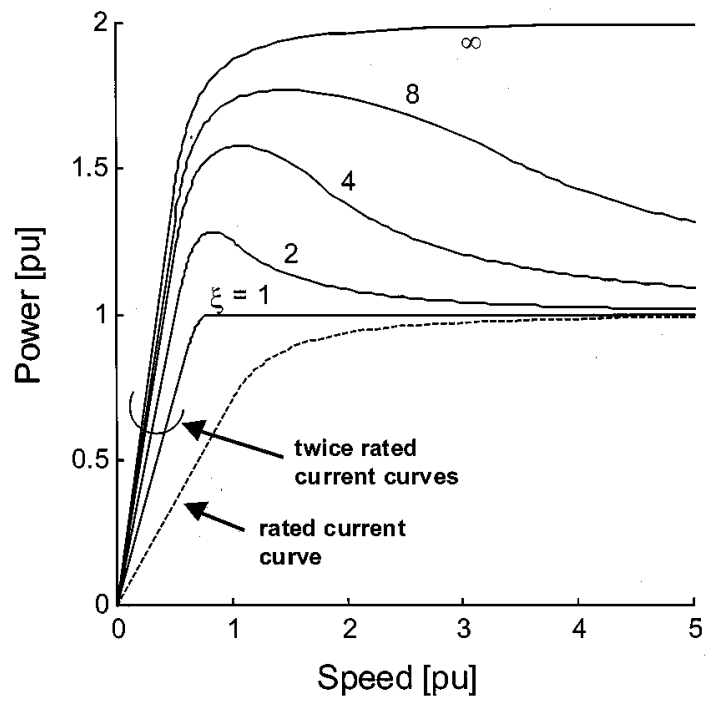

Fig. 6. Ideal field-weakening power versus speed characteristics at rated and twice rated current for optimal field-weakening IPM designs as a function of saliency ratio.

designs at rated current. Note that the shape of the field-weakening characteristic at rated current for the optimal designs is nearly independent of saliency ratio [9].

Fig. 6 shows that, with practical saliency ratios, it is not possible for IPM designs to have an ideally flat field-weakening performance at both rated current and twice rated current. The calculated overload performance improves substantially with increasing saliency ratio, although, in practice, it is likely to be strongly affected by magnetic saturation.

The reason for the limited constant-power range during overload conditions is that doubling the operating current approximately halves the normalized magnet flux linkage and, thus, shifts the location of the design in Fig. 5 away from the optimal IPM field-weakening design line. This results in a poorer field-weakening performance.
TABLE I

2.2-kW INDUCTION MOTOR STATOR DESIGN INFORMATION

\begin{tabular}{l|l}
\hline outside diameter $: 152.4 \mathrm{~mm}$ & inner diameter $: 92.08 \mathrm{~mm}$ \\
\hline stack length $: 95 \mathrm{~mm}$ & nominal airgap $: 0.39 \mathrm{~mm}$ \\
\hline rated line voltage $: 415 \mathrm{~V}$ & rated current $: 4.8 \mathrm{Arms}$ \\
\hline rated frequency $: 50 \mathrm{~Hz}$ & poles $: 4$ \\
\hline cold phase resistance $: 3.0 \Omega$ & number of slots $: 36$ \\
\hline winding : single-layer concentric, 47 turns, star \\
\hline
\end{tabular}

TABLE II

2.2-kW DESIGN INFORMATION FOR AXIALLY LAMINATED MOTORS

\begin{tabular}{l|c|c}
\hline Rotor Parameters & 2. Synchrel & 3. IPM \\
\hline lamination thickness & $0.5 \mathrm{~mm}$ & $0.5 \mathrm{~mm}$ \\
\hline barrier thickness & $0.25 \mathrm{~mm}$ & $0.4 \mathrm{~mm}$ \\
\hline barrier material & insulator & magnet sheet \\
\hline pole-piece material & brass & iron \\
\hline laminations per pole & 30 & 25 \\
\hline
\end{tabular}

\section{Prototype Motor Design ANd Construction}

The available dynamometer facility limited testing to approximately $30 \mathrm{~N} \cdot \mathrm{m}$ and $1500 \mathrm{r} / \mathrm{min}$, so a four-pole $15-\mathrm{N} \cdot \mathrm{m} 2.2-\mathrm{kW}$ induction motor was chosen to allow margin for overload testing. The design information for this stator is summarized in Table I.

The cross sections of the four synchronous rotors were shown earlier in Fig. 3.

Rotors 2 and 3 are axially laminated synchrel and IPM machines, respectively (see Table II), whose designs are based on two 7.5-kW motors built earlier [7]. Previous analysis has shown that good performance in synchrel machines is obtained by using barrier material which is half the thickness of the lamination material and nonmagnetic pole pieces. The IPM design used thicker magnet sheet $(0.4 \mathrm{~mm})$, to improve the magnet flux and resistance to demagnetization, and iron pole pieces, to improve the shape of the back-EMF waveform. Four nonmagnetic stainless steel bolts were used to secure each pole piece to the shaft.

Flexible plastic-bonded ferrite magnet sheet [7] was used for the IPM designs. This has a remanance in the range of $0.15-0.20 \mathrm{~T}$ and is available in thicknesses down to $0.25 \mathrm{~mm}$. Material of 0.4-mm thickness was used in the axially laminated IPM machine and of 3-mm thickness in the multiple-barrier designs. The magnet sheet was magnetized by exposing it to a 1-T field.

Rotors 4 and 5 are radially laminated multiple-barrier designs with three and four flux barriers per pole, respectively (see Fig. 3 and Table III). The flexible PM material allows the use of semicircular flux barriers which are a good approximation to the ideal barrier shape [3].

The amount of PM material in the multiple-barrier rotors was chosen to be comparable to that in the axially-laminated IPM design. This has 25 layers of $0.4-\mathrm{mm}$ magnet sheet $(10 \mathrm{~mm}$ total $)$ per pole. The three-barrier IPM design has three layers of 3-mm magnet sheet $(9 \mathrm{~mm}$ total) per pole and the four-barrier design has four layers of magnet sheet (12 $\mathrm{mm}$ total) per pole.

The laminations were laser cut from standard $0.5-\mathrm{mm}$ lamination material. The magnet material was preformed around cylinders of the appropriate diameter to ease insertion in the rotor. 
TABLE III

DESIGN INFORMATION FOR THE MULTIPLE-BARRIER ROTORS

\begin{tabular}{l|c|c}
\hline Rotor Parameters & 4. 3-Barrier & 5. 4-Barrier \\
\hline barriers per pole & 3 & 4 \\
\hline barrier thickness & $3.5 \mathrm{~mm}$ & $3.5 \mathrm{~mm}$ \\
\hline inter-barrier iron thickness & $5.3 \mathrm{~mm}$ & $3.4 \mathrm{~mm}$ \\
\hline lamination material & \multicolumn{2}{|c}{ Lycore $150,0.5 \mathrm{~mm}$ thick } \\
\hline thickness of outer ribs & \multicolumn{2}{|c}{$0.6 \mathrm{~mm}$} \\
\hline thickness of central ribs & \multicolumn{2}{|c}{$0.8 \mathrm{~mm}$ innermost, } \\
& \multicolumn{2}{|c|}{$0.6 \mathrm{~mm}$ remainder } \\
\hline
\end{tabular}

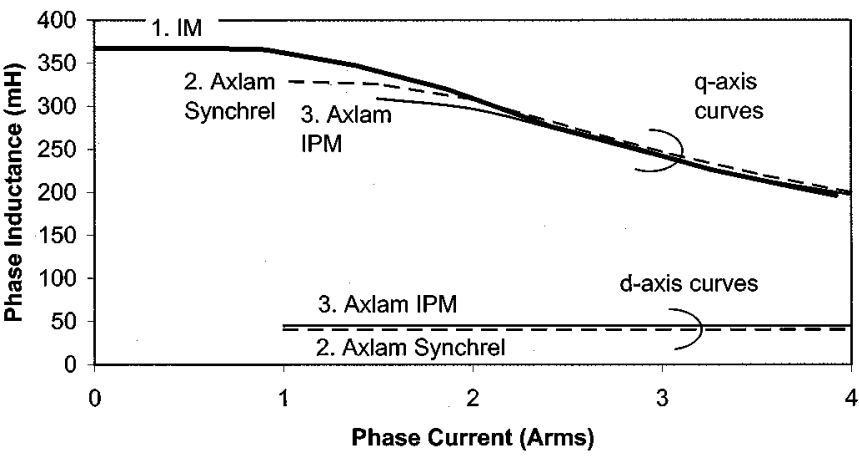

Fig. 7. Measured $q$ - and $d$-axes inductance saturation results for axially laminated synchrel and IPM machines.

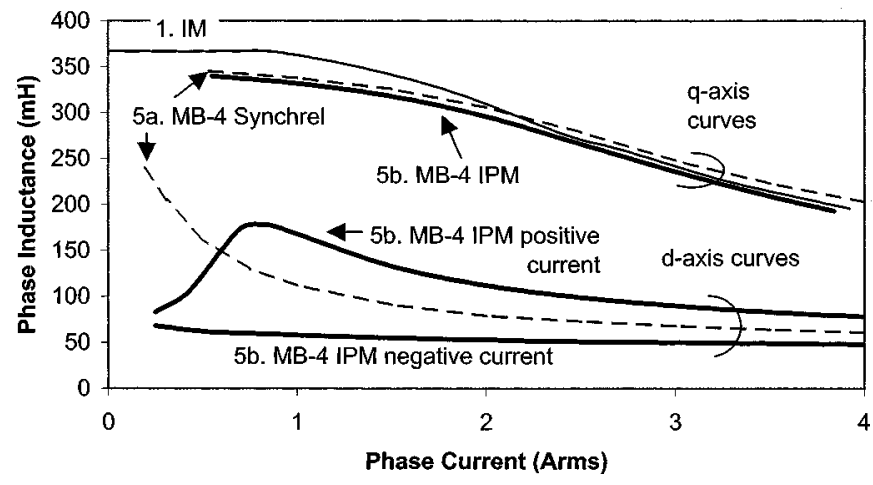

Fig. 8. Measured inductance saturation results for the four-barrier synchrel (Rotor 5a) and IPM (Rotor 5b) machines.

\section{Motor Parameter Measurement}

The key parameters for synchrel and IPM motors are the $d$ and $q$-axes saturation curves and the magnet flux linkage. The measured parameters from the prototype motors are shown in Figs. 7 and 8 and the results summarized in Table IV. An instantaneous flux-linkage method based on applying a step dc voltage to the machine and recording the resultant voltage and current transients was used. DC current injection was used to locate the rotor $q$-axis except in the case of the multiple-barrier IPM machines where this was inaccurate and an alternative ac approach was used. This was based on observing the relative phase current distribution under single-phase ac excitation.

The magnetizing and total leakage inductances of the induction machine determined from no-load and locked-rotor tests are also shown for comparison.

Fig. 7 shows that, above $2 \mathrm{~A}$, the $q$-axis inductance is independent of the rotor design and is largely limited by saturation of the stator. The unsaturated $q$-axis inductance of the axially
TABLE IV

SUMmary OF MOTOR EQUIVALENT CiRCUIT PARAMETERS

\begin{tabular}{l|c|c|c|c}
\hline & $\begin{array}{c}\text { Lq (mH) } \\
\text { unsat'd }\end{array}$ & $\begin{array}{c}\text { Ld (mH) } \\
\text { sat'd }\end{array}$ & $\begin{array}{c}\text { Saliency } \\
\text { ratio }\end{array}$ & $\begin{array}{c}\text { Back-emf at } \\
1,500 \mathrm{rpm}\end{array}$ \\
\hline 1. Induction & $\begin{array}{c}\mathrm{mag} \\
367\end{array}$ & $\begin{array}{c}\text { leakage } \\
27\end{array}$ & - & - \\
\hline 2. Axlam Synchrel & 329 & 40 & 8.2 & - \\
\hline 3. Axlam IPM & 309 & 45 & 6.9 & $84 \mathrm{~V}$ \\
\hline 4a. MB-3 Synchrel & 376 & 70 & 5.4 & - \\
\hline 4b. MB-3 IPM & 376 & 63 & 6.0 & $70 \mathrm{~V}$ \\
\hline 5a. MB-4 Synchrel & 346 & 61 & 5.7 & - \\
\hline 5b. MB-4 IPM & 340 & 48 & 7.1 & $68 \mathrm{~V}$ \\
\hline
\end{tabular}

laminated rotors is lower than the induction machine's magnetizing inductance due to the increase in the effective airgap from the rotor slotting. The unsaturated saliency ratio of the axially laminated synchrel design was 8.2 compared with 6.9 for the IPM design. The poorer saliency ratio of the IPM design is associated with the larger effective air gap in the $q$-axis due to the thicker barrier layers and the increase in $d$-axis inductance due to the use of magnetic pole pieces.

Fig. 8 shows the inductance curves for the four-barrier synchrel (Rotor 5a) and IPM (Rotor 5b) designs. This corresponds to testing Rotor 5 with and without magnets. The results for the three-barrier rotor (Rotor 4) are similar. The $q$-axis curves are comparable to the other machine types; however, the $d$-axis curves show some interesting results. For the synchrel design, magnetic saturation in the rotor ribs cause the $d$-axis inductance to be initially large but to drop rapidly with increasing current [3], [8].

For the IPM design, the measured $d$-axis inductance saturation characteristic varied with the polarity of the applied current. This is thought to be associated with the interaction of the stator flux and PM flux in the rotor ribs (see Fig. 3). Normally, these ribs are saturated by the magnet flux. For positive stator currents, the stator flux opposes the magnet flux in the rotor ribs and thus for a certain current value, the ribs come out of saturation. This results in a large change in flux linkage and, hence, inductance. For a negative current, the stator flux aids the magnet flux, and drives the ribs harder into saturation, and so a slowly dropping inductance is observed. Note also that the $d$-axis saturation curve for the synchrel is midway between the two IPM curves. Further experimental testing and finite-element analysis is planned to investigate this effect.

The $d$-axis inductance values quoted in Table IV for the multiple-barrier IPM designs correspond to the saturated negative current flux-linkage results. These values showed a good correspondence with that obtained using the measured short-circuit current and back EMF at $1500 \mathrm{r} / \mathrm{min}$ [5].

Fig. 9 shows the back-EMF waveforms for the three IPM machines. The back EMF is relatively small and varies from $16 \%$ to $20 \%$ of rated voltage at rated speed (see Table IV). From Fig. 5, it can be seen that the amount of magnet flux linkage is not sufficient for Rotors 3, 4b, and $5 \mathrm{~b}$ to reach the optimal field-weakening IPM design line, but should be sufficient to demonstrate significant improvement in field-weakening performance over the synchrel rotor designs.

The ripples in the back-EMF waveforms are due to the interaction of the rotor barriers with the stator teeth. The axially 


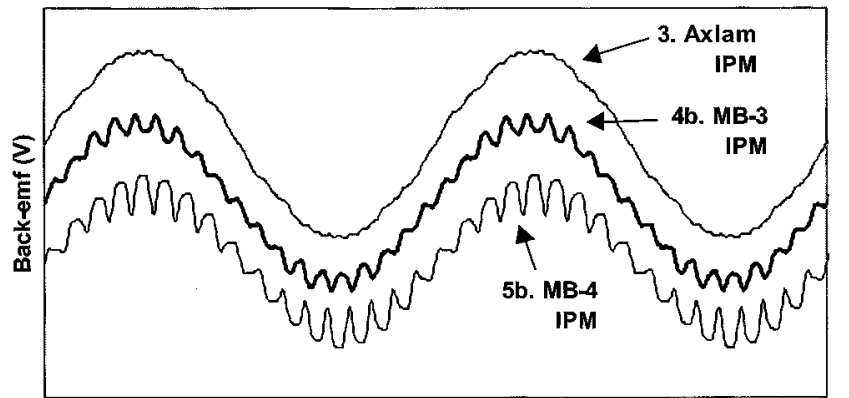

Time (ms)

Fig. 9. Measured back-EMF waveforms for the three IPM machines.

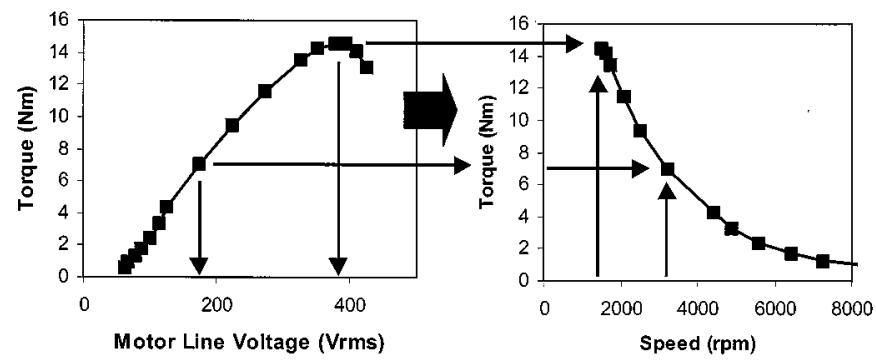

Fig. 10. Method used to estimate the field-weakening torque versus speed characteristics at rated current.

laminated design has a large number of barriers so that the resultant waveform is relatively smooth. The four-barrier design shows increased ripple compared with the three-barrier design which would increase the torque ripple.

\section{Motor DynAmometer Testing}

The dynamometer test procedure used was based on the work done by Chalmers [10] who showed that, in the absence of a suitable variable-frequency inverter, the field-weakening performance of synchronous reluctance machines could be stably tested in an open-loop manner. He used an alternator as a variable-frequency variable-voltage source, and relied on system losses to provide damping to the cageless rotor.

This method was modified by the observation that field-weakening performance is basically related to how well a machine generates torque at reduced flux within a current limit constraint. To achieve an ideal constant power performance, the machine torque should fall inversely with increasing speed and, hence, be proportional to flux (such as in an ideal separately excited dc machine). Measuring the torque versus flux characteristics at a fixed frequency corresponds to measuring the maximum torque versus terminal voltage (minus the stator resistance voltage drop) characteristic.

Fig. 10 shows the method used to estimate the field-weakening characteristics. Firstly, the maximum torque available at a given motor line voltage was measured, without exceeding either the rated current or the stability limit (see graph on left). The rated torque is the highest torque measured at any voltage. The rated speed was found by scaling the test speed $(1500 \mathrm{r} / \mathrm{min})$ by the ratio of the rated voltage divided by the voltage corresponding to rated torque. The speed corresponding to other torque values was found in the same manner. The voltage drop

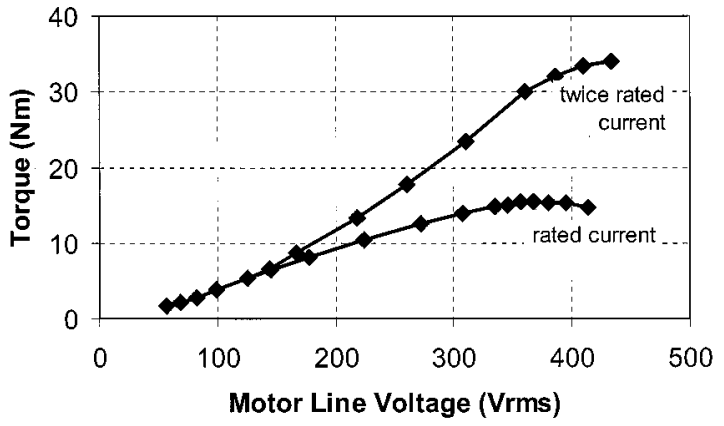

Fig. 11. Measured torque versus line voltage at $50 \mathrm{~Hz}$ for four-barrier IPM (Rotor 5b).

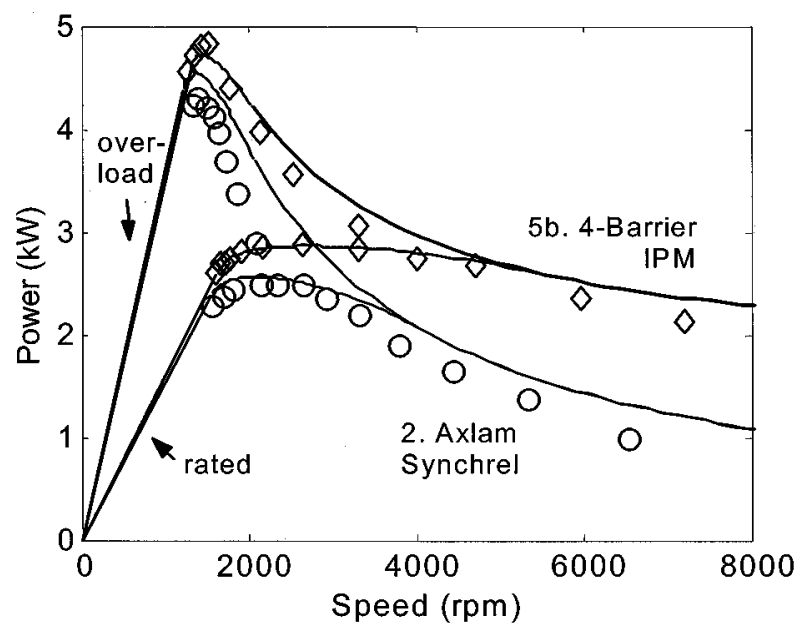

Fig. 12. Comparison of calculated field-weakening performance at rated and twice rated current (solid lines) with the estimated performance (diamonds and circles) based on experimental tests.

due to stator resistance was removed before the above scaling was performed. For the induction motor, the effect of slip was also taken into account in the calculations.

The method was repeated with a current limit equal to twice rated current to determine the overload characteristics. An autotransformer allowed line voltages of up to $480 \mathrm{~V}(115 \%$ of rated) to be applied to the motor. However, for the test motors this was not quite sufficient for the maximum overload torque point to be reached and a small extrapolation was required to estimate the maximum overload torque (see Fig. 11).

The proposed field-weakening performance estimation approach takes into account magnetic saturation but does not properly take into account the effect of iron losses. Fig. 12 shows a comparison of the calculated field-weakening performance for Rotors 2 and 5b, based on their measured inductance and back-EMF characteristics, with the estimates using the method described above. The good correlation gives confidence in the validity of the approach.

The motor performance was characterized using the test setup shown in Fig. 13. The motor under test was powered from the mains through an autotransformer. It was coupled to the dc machine which was first used to bring the test motor up to synchronous speed and then to act as a load machine. The test motor was mounted on gimbals which allowed the reaction torque to be measured using a linear load cell and readout. 


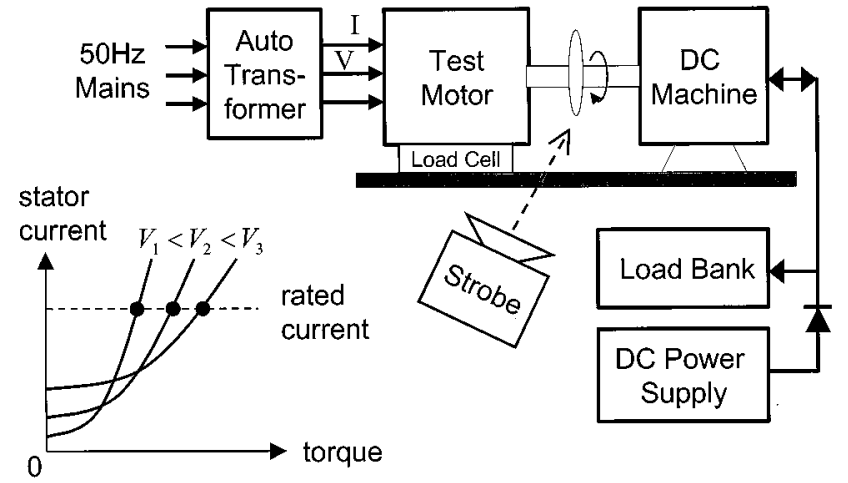

Fig. 13. Dynamometer arrangement used to perform the open-loop testing.

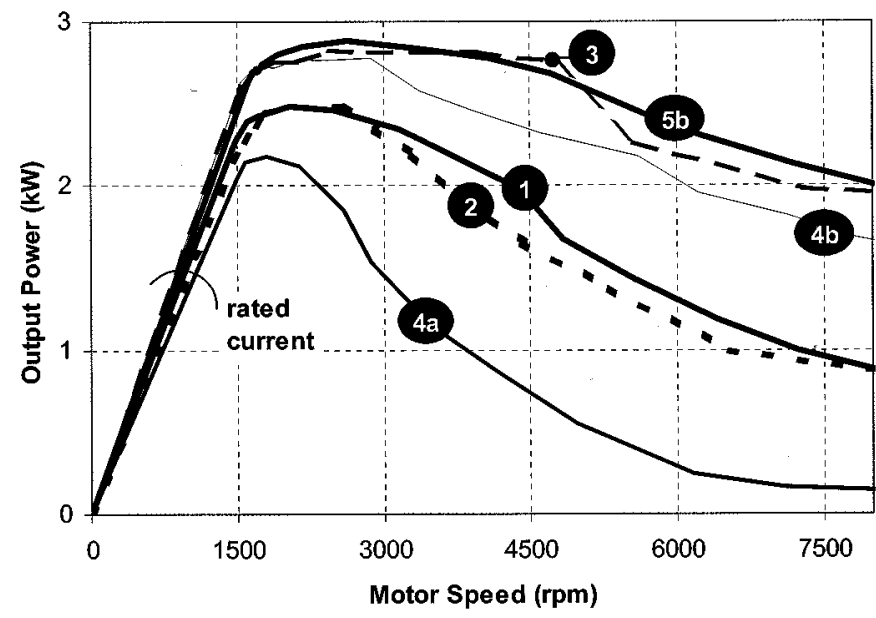

Fig. 14. Estimated power versus speed characteristics at rated current for Rotor 1: induction; Rotor 2: axlam synchrel; Rotor 3: axlam IPM; Rotor 4a: three-barrier synchrel; Rotor 4b: three-barrier IPM; and Rotor 5b: four-barrier IPM.

The test motor loading could be adjusted smoothly by varying the dc power supply output voltage. This is important to avoid pull-out because of the open-loop nature of the test [10]. At lower values of torque, additional resistance was inserted in series with the dc machine armature winding to provide smoother control. For the IPM machines, the back-EMF induced significant currents (one-half to two-thirds of rated) through the autotransformer prior to synchronization, although this did not cause any problems.

Loss of synchronism (pull-out) was a major concern during testing. At higher voltages, the resultant high currents after pull-out could demagnetize the relatively weak permanent magnets used in the IPM machines. The rotor angle was observed using a strobe flash to give an indication of proximity to pull-out. During the course of the testing, both Rotors $4 \mathrm{~b}$ and $5 \mathrm{~b}$ were demagnetized, although fortunately it was possible to extract the rotor magnets and remagnetize them. Due to the difficulty of these tests, only one IPM motor (5b) was tested under overload conditions.

\section{DISCUSSION OF RESULTS}

Fig. 14 and Table $\mathrm{V}$ show the power versus speed characteristics at rated current for six rotor configurations. Four of these rotors were tested under overload conditions and the re-
TABLE V

ESTIMATED FIELD-WEAKENING RESULTS FOR MOTORS

\begin{tabular}{l|c|c|c|c}
\hline & CPSR & $\begin{array}{c}\text { Power at } \\
\text { rated speed } \\
(\mathrm{kW})\end{array}$ & $\begin{array}{c}\text { Power at } \\
4,500 \mathrm{rpm} \\
(\mathrm{kW})\end{array}$ & $\begin{array}{c}\text { Power at } \\
7,500 \mathrm{rpm} \\
(\mathrm{kW})\end{array}$ \\
\hline 1. Induction & 2.28 & 2.27 & 1.90 & 0.95 \\
\hline 2. Axlam Synchrel & 1.98 & 2.28 & 1.63 & 0.92 \\
\hline 3. Axlam IPM & 3.41 & 2.53 & 2.77 & 1.97 \\
\hline 4a. MB-3 Synchrel & 1.49 & 2.06 & 0.73 & 0.16 \\
\hline 4b. MB-3 IPM & 2.32 & 2.55 & 2.34 & 1.75 \\
\hline 5b. MB-4 IPM & 3.10 & 2.61 & 2.71 & 2.08 \\
\hline
\end{tabular}
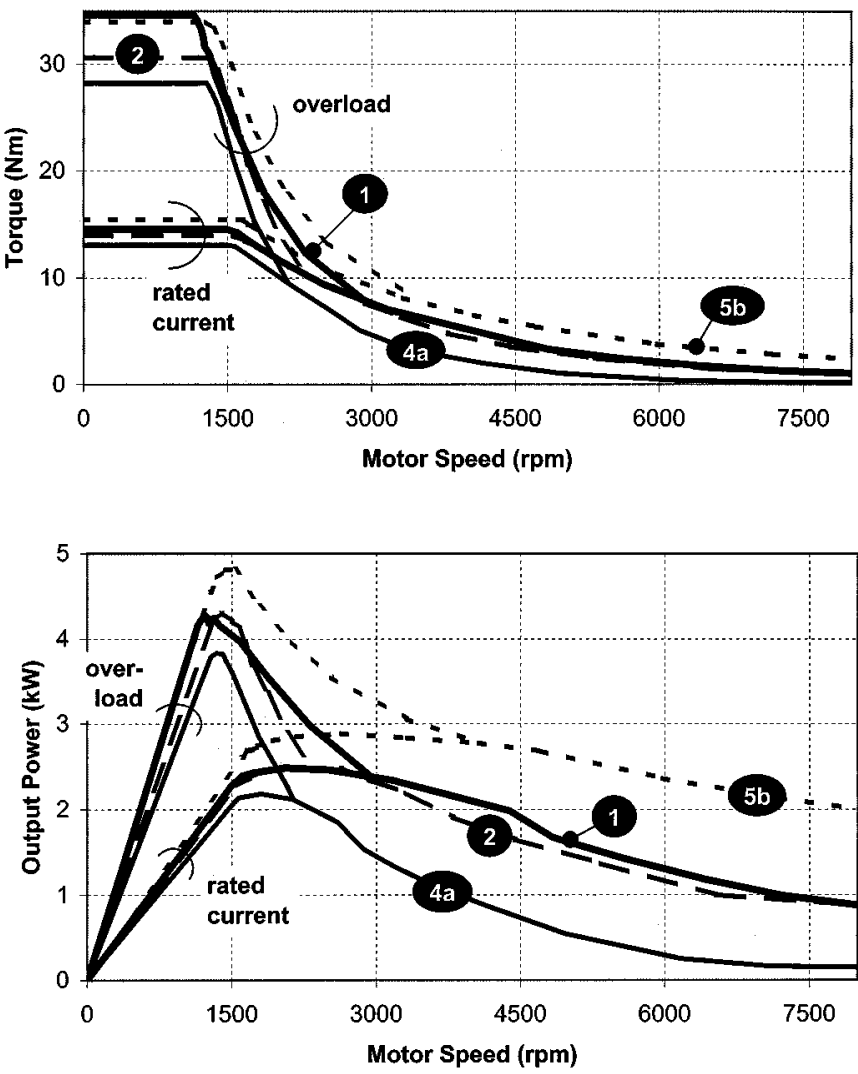

Fig. 15. Estimated torque and power versus speed characteristics at rated and twice rated current for the only four rotors tested under overload conditions. Rotor 1: induction; Rotor 2: axlam synchrel; Rotor 4a: three-barrier synchrel; and Rotor $5 b$ : four-barrier IPM.

sultant torque and power versus speed characteristics are shown in Fig. 15 at both rated and twice rated current.

The field-weakening performance of the motors can be separated into three groups. The poorest performance was produced by the three-barrier synchrel (Rotor 4a). This is associated with the ribs in the lamination design reducing the saliency ratio, especially under the high-speed low-flux field-weakening conditions. The four-barrier synchrel (Rotor 5a) was not dynamometer tested, but is expected to have similar characteristics.

Intermediate field-weakening performance was produced by the induction machine (Rotor 1 ) and axially laminated synchrel machine (Rotor 2). For the induction machine, the CPSR is approximately given by the ratio of the breakdown torque to rated torque and values of 2-3 are common for standard line-start machines. At higher speeds, the output power falls inversely with 
TABLE VI

Measured Rated Performance Characteristics

\begin{tabular}{l|c|c|c|c}
\hline & $\begin{array}{c}\text { Rated } \\
\text { Torque } \\
(\mathrm{Nm})\end{array}$ & $\begin{array}{c}\text { Rated } \\
\text { Speed } \\
(\mathrm{rpm})\end{array}$ & $\begin{array}{c}\text { Rated } \\
\text { Efficiency }\end{array}$ & $\begin{array}{c}\text { Rated } \\
\text { power } \\
\text { factor }\end{array}$ \\
\hline 1. Induction & 14.6 & 1492 & $84.3 \%$ & 0.78 \\
\hline 2. Axlam Synchrel & 14.0 & 1560 & $84.6 \%$ & 0.78 \\
\hline 3. Axlam IPM & 16.1 & 1500 & $84.4 \%$ & 0.87 \\
\hline 4a. MB-3 Synchrel & 13.1 & 1500 & $88.2 \%$ & 0.68 \\
\hline 4b. MB-3 IPM & 16.3 & 1500 & $89.0 \%$ & 0.84 \\
\hline 5b. MB-4 IPM & 15.5 & 1611 & $90.0 \%$ & 0.84 \\
\hline
\end{tabular}

speed. The axially laminated synchrel machine offered comparable performance to the induction machine. This is consistent with earlier results [7], [10].

As predicted by theory, the best field-weakening performance was produced by the IPM machines (Rotors $3,4 b$, and $5 b$ ). From Fig. 14, they produced nearly twice the output power of the induction machine at five times rated speed $(7500 \mathrm{r} / \mathrm{min})$. Note that, due to the difficulty of open-loop testing, only Rotor $5 \mathrm{~b}$ was taken to the limit of stability, while Rotors 3 and $4 \mathrm{~b}$ were tested with a conservative safety margin. Thus, Rotors 3 and $4 \mathrm{~b}$ should be capable of significantly better field-weakening performance, and may be comparable to or better than Rotor $5 \mathrm{~b}$.

The overload performance of the machines is shown in Fig. 15. The four-barrier IPM design (Rotor 5b) had a significantly greater field-weakening overload region than the induction machine. Rotor 5b's overload performance is not as good as that predicted in Fig. 6 for a saliency ratio of 7 as it is not an optimized IPM field-weakening design, and also due to the high degree of magnetic saturation at twice rated current (see Fig. 8).

Table VI shows the motor performance under rated conditions. It can be seen that compared with the induction machine, the synchrel machines had slightly lower $(4 \%-10 \%)$ rated torque while the IPM machines had slighter higher (6\%-12\%) torque.

For the induction and axially laminated machines, the rated efficiency was about $84 \%-85 \%$. This increased to $88 \%-90 \%$ for the multiple-barrier machines. The induction machine was expected to have the lowest efficiency due to its rotor copper losses.

Earlier observations have shown that axially laminated motors can have high rotor iron loss. This is thought to be due to high-frequency $d$-axis rotor flux pulsations associated with the stator slotting. The axially laminated rotor is effectively not laminated in the $d$-axis direction and so these harmonic flux pulsations produce large axial eddy currents. It has been demonstrated that this loss can be significantly reduced by cutting radial slits in the laminations to break up the axial current flow paths [10].

The power factor of the synchrel rotors was comparable to or lower than the induction machine while the IPM rotors gave a significantly improved power factor. The axially laminated machines had higher power factors, apparently due to their higher iron loss.

The no-load iron and friction/windage loss as a function of applied voltage is shown in Fig. 16 and summarized in

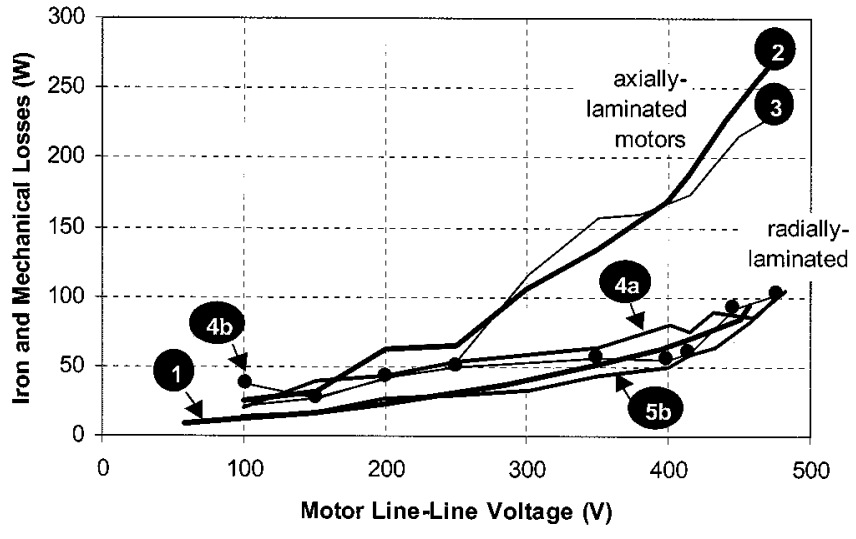

Fig. 16. Measured no-load iron and mechanical loss at $1500 \mathrm{r} / \mathrm{min}$.

TABLE VII

MEASURED IRON AND FRICTION/WINDAGE LOSSES AND OVERLOAD TORQUE AT TWICE RATED CURRENT

\begin{tabular}{l|c|c|c}
\hline & $\begin{array}{c}\text { Loss at } \\
415 \mathrm{~V}(\mathrm{~W})\end{array}$ & $\begin{array}{c}\text { Overload } \\
\text { Torque }(\mathrm{Nm})\end{array}$ & $\begin{array}{c}\text { Overload torque as } \\
\text { ratio of rated torque }\end{array}$ \\
\hline 1. Induction & 70 & $\sim 35$ & $\sim 240 \%$ \\
\hline 2. Axlam Synchrel & 187 & $\sim 32$ & $\sim 229 \%$ \\
\hline 3. Axlam IPM & 174 & & \\
\hline 4a. MB-3 Synchrel & 76 & $\sim 29$ & $\sim 221 \%$ \\
\hline 4b. MB-3 IPM & 60 & & \\
\hline 5b. MB-4 IPM & 59 & $\sim 35$ & $\sim 225 \%$ \\
\hline
\end{tabular}

Table VII. There appears to be a clear distinction between the axially laminated and multiple-barrier designs with the iron losses of the axially laminated motors being two to three times that of the multiple-barrier motors at higher values of stator flux.

The high rotor losses in the axially laminated rotors resulted in rotor heating. After an extended period of testing of the axially laminated IPM rotor (Rotor 3), the plastic-bonded magnet material was softened sufficiently by the heat to slightly squeeze out of the rotor near the pole tips. It is not clear why this area became the hottest, although it could be due to its being furthest from the shaft or due to extra losses in the solid pole pieces.

Table VII also shows the torque of the motors at twice rated current. It was found that the overload torque was comparable between the induction machine and the IPM machine (5b) while the two synchrel machines ( 2 and $4 a$ ) had a somewhat lower (9\%-17\%) output torque. The motors generally achieved somewhere between $220 \%-240 \%$ of their rated torque.

Based on the above test results, the multiple-barrier IPM design offered the most promising field-weakening characteristics. The main areas of further investigation are to examine improved magnet materials and optimization of the magnetic geometry for highest saliency ratio and low torque ripple.

From Fig. 5, it is clear that the prototype IPM designs did not have sufficient magnet flux to reach the optimal field-weakening IPM design line, which thus limited the field-weakening performance. Also, during testing of the prototype motors, it was found that the magnets were prone to demagnetization, especially under overload conditions where there are high values of $d$-axis current. It is proposed to investigate using alternative magnet types such as flexible rare-earth $(\mathrm{NdFeB})$ 
bonded magnet sheet [7] and sintered ferrite magnets. These magnet types offer higher values of remanence and greater resistance to demagnetization.

\section{CONCLUSIONS}

This paper has compared the field-weakening performance of a standard 2.2-kW induction machine with that of synchronous reluctance and IPM machines. Both axially laminated and radially laminated multiple-barrier rotors were constructed and tested in the same induction motor stator.

A procedure for estimating the field-weakening performance of the test machines at rated current and twice rated current was developed based on fixed-speed $50-\mathrm{Hz}$ load tests at reduced voltage.

It was found that the axially laminated rotors had the highest saliency ratios but suffered from high iron losses (two to three times that of the multiple-barrier rotors).

The axially laminated synchronous reluctance motor had similar rated and field-weakening performance to the induction machine, while the multiple-barrier synchronous reluctance rotor had poor field-weakening performance due to the leakage flux associated with the lamination ribs.

The multiple-barrier interior PM motor was found to offer the most promising rated and field-weakening characteristics. Compared with the standard induction machine, the prototype machine offered greater power at high speeds (twice the output power at five times rated speed), comparable overload torque, significantly better overload field-weakening performance, and higher efficiency (only two-thirds of the losses at rated speed). It is expected to offer efficient high-speed light-load performance due to its low back EMF (16\% of rated voltage at rated speed).

Future work is planned to optimize the field-weakening performance, explore alternative magnet materials and geometries for the multiple-barrier rotor, and to extend the field-weakening comparison to surface permanent magnet machines and hybrid machines consisting of part SPM and part synchronous reluctance [11].

\section{ACKNOWLEDGMENT}

The authors would like to thank S. Brand for the construction of the motors, Laser3D for laser cutting the rotor laminations, Australian Magnet Technology for the magnet material, and Brook Hansen for the induction motors and stator design information. They would also like to thank G. C. Foo and S. Tan for their support of the FE analysis and IM testing, and G. B. Kliman for helpful discussions.

\section{REFERENCES}

[1] T. M. Jahns, "Flux weakening regime operation of an IPM synchronous motor drive," IEEE Trans. Ind. Applicat., vol. IA-23, pp. 681-689, July/Aug. 1987.

[2] T. A. Lipo, "Synchronous reluctance machines-A viable alternative for AC drives?," Elect. Mach. Power Syst., vol. 19, pp. 659-671, 1991.
[3] T. J. E. Miller, D. A. Staton, and S. E. Wood, "Maximizing the saliency ratio of the synchronous reluctance motor," Proc. IEE-Elect. Power Applicat., vol. 140, no. 4, pp. 249-259, July 1993.

[4] R. Schiferl and T. A. Lipo, "Power capability of salient pole permanent magnet synchronous motors in variable speed drive applications," IEEE Trans. Ind. Applicat., vol. 26, pp. 115-123, Jan./Feb. 1990.

[5] A. Fratta, A. Vagati, and F. Villata, "Design criteria of an IPM machine suitable for field-weakened operation," in Proc. ICEM'90, 1990, pp. $1059-1065$.

[6] S. Morimoto, Y. Takeda, T. Hirasa, and K. Taniguchi, "Expansion of operating limits of permanent magnet motor by current vector control considering inverter capacity," IEEE Trans. Ind. Applicat., vol. 26, pp. 866-871, Sept./Oct. 1990.

[7] W. L. Soong, D. A. Staton, and T. J. E. Miller, "Design of a new axially-laminated interior permanent magnet motor," IEEE Trans. Ind. Applicat., vol. 31, pp. 358-367, Mar./Apr. 1995.

[8] S. Morimoto, S. Masayuki, and Y. Takeda, "Performance of PM/reluctance hybrid motor with multiple flux-barrier," in Proc. Power Conversion Conf., Nagaoka, Japan, 1997, pp. 649-654.

[9] W. L. Soong and T. J. E. Miller, "Field-weakening performance of the five classes of brushless synchronous AC motor drives," Proc. IEE-Elect. Power Applicat., vol. 141, no. 6, pp. 331-340, Nov. 1994.

[10] B. J. Chalmers and L. Musaba, "Design and field-weakening performance of a synchronous reluctance motor with axially-laminated rotor," in Conf. Rec. IEEE-IAS Annu. Meeting, 1997, pp. 271-278.

[11] B. J. Chalmers, L. Musaba, and D. F. Gosden, "Variable-frequency synchronous motor drives for electric vehicles," IEEE Trans. Ind. Applicat., vol. 32, pp. 896-903, July/Aug. 1996.

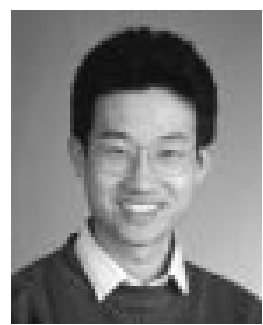

Wen L. Soong ( ' $^{\prime} 89-M^{\prime}$ '90) was born in Kuala Lumpur, Malaysia. He received the B.Eng. degree from the University of Adelaide, Adelaide, Australia, in 1989 and the Ph.D. degree from the University of Glasgow, Glasgow, U.K., in 1993.

He was an electrical engineer for four years in the Power Controls Program at General Electric Corporate Research and Development, Schenectady, NY, before taking up a teaching position in the Electrical and Electronic Engineering Department, University of Adelaide, in 1998. His present research interests include permanent-magnet and reluctance motor design and modeling, condition monitoring and diagnostics, high-power automotive alternators, and solarpowered aircraft. He is the holder of eight U.S. patents.

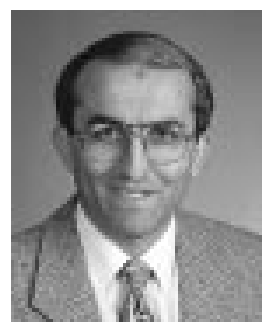

Nesimi Ertugrul (M'95) received the B.Sc. and M.Sc. degrees in electrical and electronic and communication engineering from Istanbul Technical University, Istanbul, Turkey, in 1985 and 1989, respectively, and the Ph.D. degree from the University of Newcastle-upon-Tyne, Newcastle-upon-Tyne, U.K., in 1993.

Since 1994, he has been with Adelaide University, Adelaide, Australia, where he is a Senior Lecturer. His research topics include rotor-position-sensorless operation of brushless permanent-magnet and switched reluctance motors, real-time control of electrical machines, fault-tolerant motor drives, condition monitoring, power electronic systems, and electric vehicles. He is currently engaged in research on the development of interactive computer-based teaching/learning systems involving object-oriented programming and data acquisition. He is the author of LabVIEW for Electric Circuits, Machines, Drives and Laboratories (Upper Saddle River, NJ: Prentice-Hall, 2002). He serves on the Editorial Advisory Board of the International Journal of Engineering Education (IJEE) and coordinated and edited two of its special issues on LabVIEW applications in engineering education and on remote access and distance learning laboratories. 